This PDF is a simplified version of the original article published in Internet Archaeology. Enlarged images, videos and image gallery which support this publication can be found in the original version online. All links also go to the online version.

Please cite this as: Dunlop, G. and Schofield, J. 2021 'The Technological Sublime': Combining Art and Archaeology in Documenting Change at the Former RAF Coltishall (Norfolk, UK), Internet Archaeology 56. https://doi.org/10.11141/ia.56.16

\title{
'The Technological Sublime': Combining Art and Archaeology in Documenting Change at the Former RAF Coltishall (Norfolk, UK)
}

Gair Dunlop and John Schofield

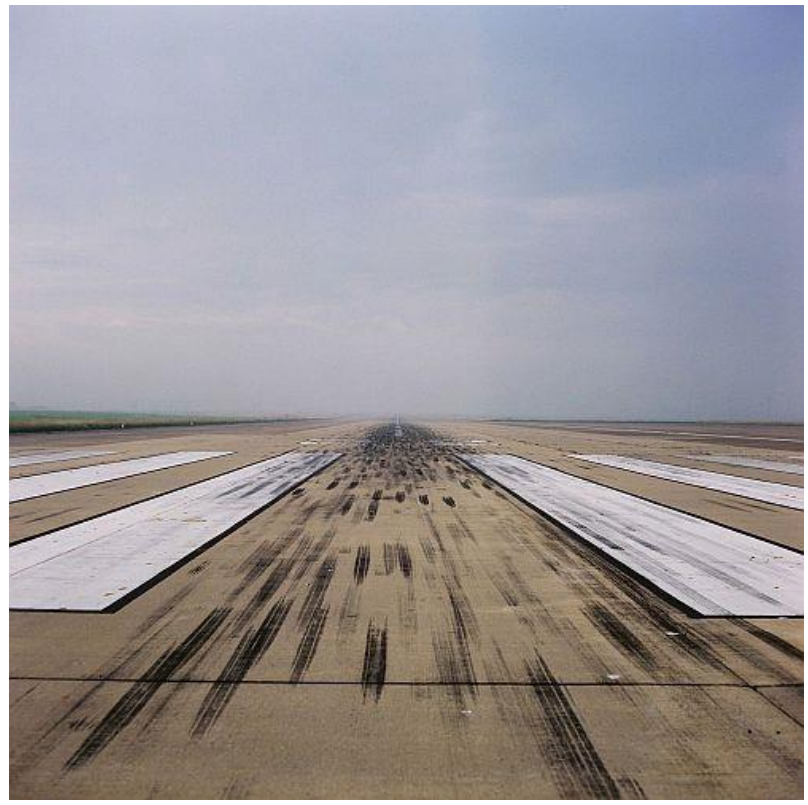

Runway 22a, Coltishall. October 2006. (C) Gair Dunlop

Since at least the 1990s, archaeologists and artists have been documenting military installations following the withdrawal of service personnel. They have usually embarked on these recording opportunities separately, experiencing these sites as derelict, lifeless places, with stripped buildings devoid of much of their meaning after their occupants have left. Archaeologists have typically created maps and made photographs. Artists have also taken photographs, but in addition made films and created soundworks. Wherever the medium and the motivation, the assumption is usually made that only those closely familiar with the rhythms and rituals of service life can begin to understand the emptiness of what remains. And being secretive military installations, creating a record during their occupation is never an option. 
Uniquely, in the months leading to the closure of RAF Coltishall (Norfolk) in 2006, the RAF granted the authors unprecedented access to record the base's drawdown and closure. The project brought artists and archaeologists together to see what could be achieved in unison, while still maintaining some degree of research independence. In undertaking this survey, three related themes emerged: the role of art as heritage practice, new thinking on what constitutes landscape, and the notion of a 'technological sublime'. Following an earlier publication, we now reflect again on those themes. In doing so, we offer this collaboration between art and archaeology (traditionally considered two distinct ways of seeing and recording) as an innovative methodology for documentation, not least after the closure and abandonment of such military and industrial landscapes, where occupational communities had once lived. In this article, the words represent our ideas; the images and films are an example of the result.

\section{Introduction}

In 1966, and ahead of its time, an Institute of Contemporary Archaeology was created by the Boyle family of collaborative artists based in London, to give context to their work 'Dig', performed first at Shepherd's Bush and later Watford. As Sebastian Boyle later said:

For us [the Institute] served several purposes, firstly it was a cover we started using when people came up whilst we were doing our site work. We found that if we said we were artists we would get tied up for ages in 'you call that art' type conversations etc., when we had very little time to stop and chat. Contemporary Archaeology sounded believable and reduced follow-up questions. Secondly, it fitted in with our approach of trying to be objective, to see the world as it is, accepting reality and not trying to embellish it for the sake of art. (Personal communication)

In a way that's what happened at Coltishall, albeit with archaeologists and artists operating together under the aegis of an archaeological study of a fast-changing historic landscape (and for a more detailed account of the rationale and the wider project, see Schofield et al. 2012).

The project (which ran through 2005-6) had its origins in various other projects and discussions held over the course of the previous decade. Key references during the project's formative stages and execution included: Buchli and Lucas 2001, GravesBrown 2000 and McAtackney et al. 2007 for contemporary archaeology; and Renfrew $\underline{2004}$ and Schofield 2006 for contemporary art and archaeology. Together these projects and discussions emphasised the gradual erosion of disciplinary boundaries and witnessed the emerging connections in particular between art and archaeology in the context of both heritage practice and thinking around ideas of place, community and landscape. In addition to English Heritage (now Historic England) staff (Wayne Cocroft and John Schofield), and members of Atkins Heritage (Sefryn Penrose, Tony Lee and Andrea Bradley), the project involved three artists: 
Louise K. Wilson had previously worked alongside English Heritage survey teams in compiling a landscape study of the missile testing range at Spadeadam (Cumbria) (Cocroft and Wilson 2006; Wilson 2007; Wilson nd); Angus Boulton had documented numerous former Soviet bases in the former German Democratic Republic (Boulton 2006; 2007a; 2007b). Gair Dunlop had previously made artworks that explore entropic Modernism: the New Town, the film archive and the memory of progress. It is his work that we focus on here. The Coltishall project was commissioned by English Heritage's (now Historic England's) Characterisation Team, and led by John Schofield.

From an English Heritage perspective, the focus of this study was not simply the documentation of a soon-to-be abandoned military site as a finished place (as much as any place is ever 'finished', e.g. Pred 1984) or to create a foundational 'point in time' study to inform future management, both common responses at the time by English Heritage survey teams to 'disposals' by the Defence Estate. Rather, the more challenging aim was to document Coltishall as a place in transition, capturing part of the ongoing and infinite process of 'becoming'. With the RAF providing virtually unlimited access to the historic and iconic station at RAF Coltishall, a station with a strong sense of place and community, and where the trauma of closure was therefore likely to be keenly felt among its personnel and alumna, this was an ideal opportunity for experimenting with innovative methods of recording process while also documenting a place in time.

\section{Coltishall in its Cultural and Social Landscape}

RAF Coltishall was created at the start of the Second World War. Strategically located 10 miles $(16 \mathrm{~km})$ north-east of Norwich, close to England's east coast and near the village where many of the station's officers lived (and in many cases also later retired), Coltishall served as a fighter station throughout the Second World War, later becoming a base for night fighters and then ground-attack aircraft until its closure in 2006. The history and character of the site is described in some detail elsewhere (Cocroft and Cole 2007; Schofield et al. 2012). Here we wish to emphasise the social fabric. In terms of the physical place, therefore, we merely present this as backdrop to the actions of those who were living and stationed at Coltishall in 2006: the size of the place, its status as an occupational community (after Salaman 1974), its symmetrical and closely familiar layout to those who lived and worked on RAF stations, and its character, as a wide, flat, windswept and diffuse place in a remote part of eastern England. 
Like RAF stations and military air bases the world over, Coltishall was extensive, barely visible from one side to the other. As well as being a front-line military base, it was also home and workplace to a fluid population of around 2000 personnel and their families for over 60 years. It was like a small town, a place that provided all that its occupants required. Given the nomadic nature of service life, with postings typically coming at regular two- to three-year intervals, RAF stations helpfully provided a sense of continuity through their similarity. Consistency in their plan-form was important for ensuring that new arrivals gained a sense of familiarity and would feel quickly at home. As with towns, different areas within RAF stations perform specific functions and display distinct character as a result: the flying field and technical areas; workshops and the places of industrial endeavour; the various domestic or housing areas, organised by rank with clear distinctions in housing provision for officers, sergeants and airmen; administrative offices and the social hubs - the messes; infrastructure in the form of schools, churches and shops; and leisure facilities - pitches of various kinds, squash courts and a swimming pool. These 'character areas' can be easily mapped in the years following abandonment, simply from the distinctive physical traces of their architecture and configuration. At Coltishall, as on comparable sites, servicemen, their families and privately contracted employees interact with these different character areas in diverse ways according to their rank and role. It is these social relationships that are harder to reveal once the people have left.

\section{Aims and Objectives}

This difficulty in understanding how people interacted with and valued buildings and spaces after a site's abandonment is the reason why most records of abandoned heritage sites lack the vitality of human experience (Shapland 2020; and see Cocroft and Schofield (2019) for an example of using archaeological methods to attempt to understand the social spaces of an abandoned military site). One response to this challenge is to develop new approaches to capturing these relationships in ways that might incorporate both the physical and the social dimensions. In the case of Coltishall, we felt this could best be achieved not through traditional archaeological or heritage recording methods, but through close collaboration with artists who, in this case, had already worked in different ways with and on the military estate. We also saw value in research independence, which in this case took the form of conversations around our individual experiences, allowing all participants to operate independently yet also sharing ideas. This would allow the creation of both individual records of the site as well as a more collaborative or at least collective output. A previous publication reports on the latter (Schofield et al. 2012). Here we focus on the former. The crux of this methodology was the interaction between participants, which mostly took the form of ad hoc conversations held in situ between different combinations of participants. These conversations usually occurred as chance encounters, at various random places on this vast and windswept site. The artistic responses (comprising works in film, photography and sound) were thus separate from one another, and entirely separate from the archaeological recording of spaces and buildings that was also taking place. We were all looking for different things it seemed, yet all for the same purpose. Fieldwork was conducted during the process of 
drawdown, while the site's occupants were still there but at a time when their sense of place was perhaps heightened by the imminence of closure and their final departure. The aim of our experiment was to document and record a landscape that was changing, both physically and socially, capturing some of the ways in which it was changing and the various ways that people engaged with that process. In other words we wanted to capture the unmaking and remaking of heritage, on the ground, as it happened.

The purpose of the Coltishall study was therefore two-fold. First, to create a documentation of RAF Coltishall, not simply in its increasingly abandoned state, but to chart its transformation from front-line station to whatever happened next (and with the 15-year period of reflection, we can present part of the story of this afterlife, unbeknown to us at the time). Second, to develop and field-test a methodology for documenting this change. Specifically, by working independently but for the same purpose, we wanted to better understand what artists and archaeologists might contribute to documenting and interpreting places of this complexity, being highly structured, controlled and ritualised spaces where particular rules apply and can only usually be fathomed by those within (or closely familiar with) the system.

\section{Documenting Drawdown: thinking through a method}

At first glance, artists and archaeologists would seem to use very different languages as well as different techniques, communicating with their respective audiences in very distinct ways. On closer examination, however, many of the conceptual approaches offered in contemporary arts practice offer valuable tools to understanding place, atmosphere and the persistence of memory, just as archaeology can be artistic (e.g. Schofield 2006). As stated above, all three artists involved in the Coltishall project had a personal relationship to militarised space, whether through family history or campaign activism. Through personal connections to English Heritage staff and projects, and following an expression of interest, these personal relationships with militarised space were re-stimulated in different ways at Coltishall during an initial period of site access and familiarisation, not least during conversations between the artists and RAF personnel and, in some cases, a reacquaintance (comfortable or not) with militarised space, dress codes and behaviours.

[VIDEO ONLINE ONLY] Simulator/Realtime: Footage of the path taken around and through RAF Coltishall by a pilot in the Jaguar simulator, paralleled by an attempt to take the same route in a vehicle in the real world. Stopped at gunpoint by a patrolling RAF Regiment Land Rover; this turned into a very fast 'justify your methodology' conversation. Film by Gair Dunlop.

Following this initial familiarisation phase, virtually unlimited access to all areas of the site was confirmed by the RAF and the fieldwork could begin. The visual, sonic, and digital arts practices adopted variously by the three artists are all hybrid forms of 
knowledge and information gathering. In the following sections, we reflect on these various artistic perspectives and their contribution to shaping the method by which we attempted to document change at RAF Coltishall. Our methodology was simple: to record what we witnessed, in real time, using whatever means seemed the most appropriate. Unusually for an English Heritage project, there was no brief, beyond the aspiration to record what felt important or somehow representative of this iconic and much-loved station during this critical stage in its history. The thinking behind this approach (such as it is), the methods we adopted, and the results of our encounters (represented in the selection of photographs and films we have included here), are given context in the form of brief reflections structured around four themes that we developed over the course of our visits: Sign into abstraction; Reverberation; Mirroring through Geography; and Mirroring through Simulation.

\subsection{Sign into abstraction}

Within this theme, we explored the proposition that a knowledge of art history makes a trip around the station a visually rich and information-laden experience. The cultural memory in this case is informed by the work of war artists such as Paul Nash (Aerial Creatures) and Eric Ravillious, and by the literary insights of writers such as Rex Warner (The Aerodrome, 1941). The imagination is immediately engaged through an intense curiosity and effort to match our received ideas with the reality around us.

One expects the panoply of concealment all around on a military airfield; remnants of sandbagged shelters, overlaid by larger postwar structures, regulation colours and drabness. What is less expected is the brightness and vividness of the signage and area marking. In an environment where fast-moving aircraft and fragile humans coexist, signalling of direction, shelter and decision points are bold, large, and very reminiscent of gigantic abstract expressionist sculptures and paintings. The functional universality of signage and ground marking across all RAF stations, combined with the similar design and layout of their architectures, meant that mobile personnel would feel and act in a coordinated manner wherever they happened to be posted. As the base slowly approached closure, these functional signs and behavioural cues were readable by fewer and fewer people. They drifted from purposeful signification into striking, often beautiful, aesthetic experiences. The writing of J.G. Ballard offers an exemplary model in the shifting of surface signs from common vocabulary into solitary muse. (See The Terminal Beach (1964) and The Atrocity Exhibition (1972) for examples of a landscape where personal obsession, advertising, technology and the spirit of the Cold War fuse.)

\subsection{Reverberation}

Memory and history restored to their original setting play a vital part in the work of Louise K. Wilson. Her work at the National Trust owned site of Orford Ness in Suffolk, A Record of Fear (Wilson nd), used the horrifying possibilities of the Atomic Weapons Research Establishment (AWRE) test labs in two main ways. The restitution of sound to the abandoned laboratory structures brought a phantom presence of 
centrifuge machinery to the entropic laboratories. The subsonic sound and vibrating ruins allowed visitors to experience the processes of Cold War science viscerally. Secondly, the re-purposing of other test chambers and a control room as performance arenas for poignant choral interventions gives some clues as to her approach at Coltishall. Building on these prior experiences, we anticipated a focus on the capacity to combine sonic landscapes of Coltishall during closure with dialogue. Wilson is fascinated by the idea of reunions around expert cultures, and insights from attending these events at Coltishall is juxtaposed with video and sound from the sites of memory.

\subsection{Mirroring through geography}

At Coltishall, the apocalyptic imaginary of the runways and the final rituals of camaraderie and farewell inspired Angus Boulton's film '04/22' (2008). It can be seen as a pastoral version of his earlier '08/26' (2007) which counterpoints ambiences and architectures of airbases on opposing sides of the Iron Curtain. The specific architectures of Hardened Aircraft Shelters and runways facing each other across the North Sea are supplemented in his Coltishall film with the specifics of pilots and crew preparing and posing with their ageing aircraft for one last time.

\subsection{Mirroring through simulation}

[VIDEO ONLINE ONLY] Jaguar flight simulator. Wales Incident. Inside the flight simulator at RAF Coltishall, strange fantasy worlds were enabled; while it is impermissible to film sensitive terrain and real training missions, I filmed anti-aircraft missile avoidance in North Wales. The realtime terrain wrapping onto geographically accurate frames leads to strange village and field effects. The Menai Bridge flythrough was irresistible. Film by Gair Dunlop.

At Coltishall, an institutional half-life persisted after the airfield closure in March 2006. A Third World War, Middle East invasion, and Balkans crises continued to take place on a regular basis in a nondescript industrial building on the site. The flight simulator became a major focus of interest for Gair Dunlop. During the twilight months of the Jaguar flight programme at Coltishall, as elsewhere across the RAF, the simulator was kept running. This was partly to relieve pressure on the fragile aircraft, but also in the hope that Jaguar aircraft would continue in service in other countries requiring pilots from far and wide to attend Coltishall for virtual training. Meanwhile, RAF pilots drove the 95 miles from RAF Coningsby in Lincolnshire to be trained. After two hours on roads crowded with agricultural and goods vehicles, they would don their flight clothing, cover that with Nuclear Biological Chemical (NBC) layers, enter the half-dome, and practice evasion techniques, missile attacks, technical problems and in-flight refuelling. A sense of anarchic playfulness crept into their practice; suspension bridges were particularly popular to fly through or under. Pilots' lives had been transplanted northwards, and their exhausted aircraft would soon be sent for scrap, but in the meantime, pilots could still fly from the virtual Coltishall, which 
retained all its fixtures and fittings even as their real-world equivalents were being dismantled and dispatched.

The 'electronic false-day' (Virilio 1991, 14), represented by the pilots' ability to cling to the enduring virtual structure, became a paradoxical locus for nostalgia. (For further still and video images of the flight simulator, see http://www.atomtown.org.uk/dispersals.html)

Both these mirroring projects draw on the Situationist concept of 'the dérive' (Debord 1958), an open journey through space, intended to sense its atmospheres and to discover the overlooked, the places ignored because of unconscious hierarchies of value assigned to differing architectures. The relationship of this concept to the archaeological concept of landscape characterisation (recognising what characteristics render a place different or distinct from those around it) for us was obvious.

\section{The Technological Sublime}

As the final closedown drew nearer, base personnel became increasingly focused on the closure parade and flypast. It was clear that this display was to function as an internal marker; the public were invited, but the meaning and emotional resonance of the departure was to be marked for the RAF itself. Video observation and recording of behaviour on site became inflected by an awareness of this significance. The day of the Closure Ceremony was grey and showery. Flags were prepared for laying up, prayers were said, and memories of the war dead were invoked. Chief of Air Staff, Air Marshal Sir Jock Stirrup, spoke warmly of his memories as a Jaguar pilot at the base. The band, the speeches and the audience quietened. Eyes scanned the horizon. Sure enough, distant dots appeared to the south-east, growing rapidly in size to a skyful of roaring metal, gone as soon as fully perceived. Coltishall was over. The RAF had lost its Eden.

[VIDEO ONLINE ONLY] Dispersals. Observations of the airfield as a lived environment, a major-scale industrial workplace, and as a balance between alertness and idyll. Film by Gair Dunlop.

Concepts of 'the Sublime' as a category of experience derive from aesthetic theory, in particular Romantic Landscape conceptions of beauty, wildness, excess and fear. The 'Technological Sublime' is a concept elaborated by David E. Nye (1996) from an original idea by Leo Marx. Whereas the natural sublime is posited as an experience of 'agreeable terror' or an experience where potential loss of self-hood faced with the immensities of nature is resolved, the technological sublime is seen as a locus of terror or immensity experienced in the face of man-made environments or spectacular events. Events or sites evoking this emotion become important elements in national identities; the flyover, the dam opening, the bomb test.

In the case of the closure parade, there was a chronological paradox, in that the sense of immensity was generated by obsolete machines. Preceded by Hawker Hurricane 
and escorted by a new Typhoon Eurofighter, a 'Diamond Nine' formation of Jaguars hurtled over the parade ground and into history. The past and the future represented by Second World War aircraft and the 'new' Eurofighter - bookended their farewell.

\section{A New Beginning}

But is it ever really over? The departure of the final aircraft, amid elaborate closure ceremonials, took place on 1 April 2006, but the final closure ceremony was a more muted affair on 30 November. Notwithstanding the sombre mood, fast-car enthusiasts among the audience turned the runway into an impromptu drag strip. During the interim period, the airfield was assessed as a potential high-security annexe for Norwich International Airport, but this was not acted upon. During the immediate post-closure period, a number of temporary, makeshift and utopian proposals were mooted. Jarrolds, the long-established Norwich printers, were planning to move their city-centre printing works to the site, using the largest hangar spaces. The 2008 financial crisis destroyed that option and indeed the whole of Jarrold's printing operation and the company has re-configured itself around its property interests and its well-liked family department store.

The most bizarre proposal for the site came from architectural practice Situ Plan Ltd. Known mainly for landscape and infrastructure projects in Saudi Arabia, their masterplan and concept designs for 'RAF Coltishall Eco Village' involved building a range of ecological housing on the runways, taxiways and aprons, digging out the grassy areas around and flooding them to make water meadows and ponds. The carbon paradoxes and impracticality of such a proposal are astonishing, and it unsurprisingly went no further than a thought experiment. Traces of the project can be seen online.

What actually happened is that a mixture of public and private uses evolved piecemeal over time. Name change has been key to generating a new sense of place. It's been renamed as Scottow Enterprise Park, in the village of Badersfield, itself newly minted as the name for the sold-off streets of Officer and Married Quarters. It marks the connection of the village to Coltishall's best-known Second World War figure, the legless Hurricane pilot Douglas Bader. The site aims to generate new and high-tech businesses alongside public sector facilities. Initial use of hangar space for a police riot training facility was followed by the fencing and renovation of 'other ranks' barrack blocks as a low-security prison. HMP Bure became operational in November 2009 , and is for 'low risk' male sexual offenders. Despite the utopian lure of a water park and eco-village, the grassy surrounds of the airfield have been filled with a $50 \mathrm{MW}$ solar array, and the technical areas and some of the hangar spaces have been leased by Swift Aviation, who intend to build and test a new aerobatic trainer on site. Raptor Aerospace have started technical development of rocketry technologies. A temporary and sombre use of a small area of the hangar apron areas was as a temporary morgue during the second COVID-19 wave, when Norwich facilities became overwhelmed. 
One of the original proposals for site use was as an immigration detention centre. In response to an angry local reaction, this use was shelved. However, by January 2021, around 40 refugees, mainly from Sudan and Syria, were being housed and detained (or not detained depending on the news source) in the former Officer's Mess. This dispersal, reduced from the original 90, is another result of COVID-19, and previous accommodations being deemed unsuitable. Complaints from residents, supported by a local activist group, include: cold, inadequate accommodation, poor food, and a lack of transport and communication. A hunger strike has taken place. After hearing about this, a group of people from the nearby village of Coltishall stood outside the gates of the building to show support to the asylum seekers inside. Broadland MP Jerome Mayhew said: 'The rural location of the asylum centre in the Jaguar Buildings is widely recognised as being unsuitable for anything other than a short-term emergency stopgap to keep asylum seekers off the streets during the Covid pandemic'. A news report of 7 February 2021 described the decision to relocate the asylum seekers, the principal reason given being Coltishall's remote location. An image accompanying the article showed an asylum seeker's bedroom in the former Jaguar Building. The numbers on the door represent in microcosm the wider changes that have occurred here over the past 15 years: the RAF personnel's official plate depicting 'Room 214' replaced by the asylum seeker's 'Room 180' written above in green 'Sharpie'. And where once, presumably, there was a name, for the asylum seeker the slot for the insertion of a name plate has remained empty.

Yet even in this latest chapter, there is continuity of sorts: aircraft remain on the site; and people continue to occupy the Officers Mess. From the air, as on the ground, this remains very obviously a former military airbase, and this footprint at least is likely to remain for centuries if not millennia to come.

Thus a place is never finished. Heritage is never fully made. Change is constant, whether transformational (demolishing an iconic landmark such as an industrial chimney) or subtle (rewilding, for example, the weeds and grasses making their slow but steady inroads, working their way out through the cracks in the asphalt). At Coltishall, by combining artistic practice with an archaeological perspective, we document both types of change while also capturing some of the social interactions, impacts and responses that accompany these changes.

\section{Conclusion}

The words of this essay present some of the ideas behind our experimental approach, the thinking that went into it, and how being at Coltishall helped to shape these ideas on the ground, on the day, often through direct experience (for example talking with operators in the flight simulator) or through solitary reflection on remote and windswept parts of the slowly rewilding flying field. In a sense there is no methodology, no template to be applied at comparable sites undergoing closure or transformational change. In that sense there is no lesson to pass on. Yet the experience we can relay is that, at Coltishall, the methods were not laid out in advance but rather evolved from ideas, experiences and conversations, slowly emerging, like the grasses through cracks in the concrete. This was an approach 
grounded formally in principles of trial and error: 'let's just see what happens'. While such an approach might appear very unscientific to archaeologists, it is not unfamiliar to artists. Yet it was through this method that our characterisation emerged, albeit alongside the more conventional landscape characterisation (e.g. Fairclough 2008), complete with architectural details and building histories based around old maps and field inspections. The words of this essay describe our approach and our thinking. The results of our project, the documentation (or a part of it, focused on the work of Gair Dunlop) appear in the form of accompanying images and films.

Coltishall has been an experiment in documenting, assessing and interpreting a contemporary site during a process of transformative change. The assertion that visual inquiry can work in different ways to the textual has been affirmed by this project. As an example of the project's transformative impact on its researchers, the experiences of working with technicians and military personnel on site at Coltishall has had a radical effect on Gair Dunlop's approaches to other militarised or hermetic environments such as nuclear research facilities, and on his understanding that meaning in relation to site is co-created rather than individually authored. We have also established how film, which explores lived experience and the uses of the site, contrasts with the stillness of photography.

Even at the time of our encounters in 2005/6, the site still comprised a militarised landscape. It was also therefore an industrial landscape and a technological space, but one that is now transitioning into a new phase in which infinite new pasts will be created. This is not the change over millennia or over centuries with which archaeologists are more familiar. These are changes that might occur over the course of a year, or less. At Coltishall we have attempted to devise new methods and perspectives (thought experiments alongside methodological innovation) to record the subtle changes that often escape the archaeological lens altogether: changes within a day, as people move out of their office for the final time; the closing marchpast or fly-past and encountering a virtual landscape that no longer exists in reality. Together, these microhistories comprise those 'blink of an eye' moments: the ceremonies alongside everyday rituals that mark out change and which remain as memories. In this sense the project followed in the spirit of work by the Boyle family, reading the landscape in a way that sought to be objective in recognising its transformations, to see the world as it is, accepting reality and not trying to embellish it for the sake of art.

\section{Acknowledgements}

The Coltishall project has been collaborative from the outset. As well as the two authors, the project also involved: Angus Boulton (previously Manchester Metropolitan University), Louise K. Wilson (University of Huddersfield), Steve Cole and Wayne Cocroft (formerly and still of Historic England, respectively), Angela Weight (an independent consultant and curator), and Sefryn Penrose, Andrea Bradley and Tony Lee (all previously of Atkins Heritage). We are all grateful to the Defence Estate and RAF personnel at former RAF Coltishall for their support, guidance and 
encouragement in undertaking this work. The authors are grateful to Mark Edmonds for his thoughtful comments on an earlier draft of this paper.

\section{Bibliography}

Ballard, J.G. 1964 The Terminal Beach, London: Victor Gollancz.

Ballard, J.G. 1972 The Atrocity Exhibition, London: Jonathan Cape.

Boulton, A. 2006 'Film making and photography as record and interpretation' in J. Schofield, A. Klausmeier and L. Purbrick (eds) Re-mapping the Field: new approaches in conflict archaeology, Berlin: Westkreuz-Verlag. 35-38.

Boulton, A. 2007a 'Cood bay Forst Zinna' in J. Schofield and W. Cocroft (eds) A Fearsome Heritage: Diverse Legacies of the Cold War, Walnut Creek: Left Coast Press. 181-92.

Boulton, A. 2007b Restricted Areas, Limited edition of 5000, Manchester Institute for Research and Innovation in Art and Design (MIRIAD), Manchester Metropolitan University and The Wapping Project.

Buchli, V. and Lucas, G. 2001 Archaeologies of the Contemporary Past, London: Routledge. https://doi.org/10.4324/9780203185100

Cocroft, W.D. and Cole S. 2007 RAF Coltishall, Norfolk: A Photographic Characterisation, English Heritage Research Department Report Series 68/2007. https://research.historicengland.org.uk/Report.aspx?i=14579

Cocroft, W.D. and Schofield, J. 2019 Archaeology of the Teufelsberg: Exploring Western Electronic Intelligence Gathering in Cold War Berlin, London:

Routledge. https://doi.org/10.4324/9780429442629

Cocroft, W.D. and Wilson, L.K. 2006 'Archaeology and art at Spadeadam Rocket Establishment (Cumbria)' in J. Schofield, A. Klausmeier and L. Purbrick (eds) Remapping the Field: new approaches in conflict archaeology, Berlin: Westkreuz-Verlag. $15-21$.

Debord, G. 1958 'Theory of the Dérive', International Siuationniste 2, 62-66.

Fairclough, G. 2008 [2003] "'The long chain": archaeology, historical landscape characterisation and time depth in the landscape' in G. Fairclough, R. Harrison, J. Jameson Jnr and J. Schofield (eds) The Heritage Reader, London: Routledge. 408-24.

Graves-Brown, P. (ed) 2000 Matter, Materiality and Modern Culture, London: Routledge. 
McAtackney, L., Palus, M. and Piccini, A. (eds) 2007 Contemporary and Historical Archaeology in Theory: Papers from the 2003 and 2004 CHAT conferences, British Archaeol. Rep. International Series 1677, Oxford:

Archaeopress. https://doi.org/10.30861/9781407301150

Nye, D.E. 1996 American Technological Sublime, MIT Press.

Pred, A. 1984 'Place as Historically Contingent Process: Structuration and the TimeGeography of Becoming Places', Annals of the Association of American Geographers 74(2), 279-297. https://doi.org/10.1111/j.1467-8306.1984.tb01453.x

Renfrew, C. 2004 Figuring It Out. The parallel visions of artists and archaeologists, London: Thames and Hudson.

Salaman, G. 1974 Community and Occupation: An Exploration of Work/Leisure Relationships, Cambridge: Cambridge University Press.

Schofield, J. 2006 Constructing place: When artists and archaeologists meet [ebook], Proboscis. http://diffusion.org.uk/?cat=16

Schofield, J., Cocroft, W., Boulton, A., Dunlop, G. and Wilson L.K. 2012 '"The aerodrome": art, heritage and landscape at former RAF Coltishall', Journal of Social Archaeology 12(1), 120-42. https://doi.org/10.1177/1469605311426549

Shapland, M. 2020 'Capturing the spirit of singular places: a biographical approach to historic building recording', Post-Medieval Archaeology 54(1), 18-

41. https://doi.org/10.1080/00794236.2020.1750142

Virilio, P. 1991 Lost Dimension, New York: Semiotexte.

Wilson, L.K. nd A Record of Fear, Limited edition of 500, The National Trust and Commissions East.

Wilson, L.K. 2007 'Out to the waste: Spadeadam and the Cold War' in J. Schofield and W. Cocroft (eds) A Fearsome Heritage: Diverse Legacies of the Cold War, Walnut Creek: Left Coast Press. 155-80. 